\title{
DISCUSSÃO DA GÊNESE DO PROTOMINÉRIO DE MANGANÊS DE FÁCEIS ÓXIDO- -CARBONÁTICO DENOMINADOS "BANDARRITO", MUNICÍPIO DE JACARACI, BAHIA
}

\author{
RÔMULO MACHADO*
}

\begin{abstract}
The Bandarra manganese deposit is located in the south portion of the State of Bahia within the volcano-sedimentary sequence of the supposed Licínio de Almeida greenstone belt. The lithologic units of the area consist, from base to top, of micaschists, iron-formation, micaschists, amphibolites and quartzites. Metamorphism reached the almandine-amphibolite facies. The ore bodies are lenticular layers within irom-formation and are made up of jacobsite, hausmannite, bixbyite, secondary manganese oxide $\left(\mathrm{MnO}_{2}\right.$ group), hematite, carbonate with manganese, alleghanyite, spessartite, tephroite and other manganiferous silicates. The coexistence of primary manganese oxides with carbonate in protore reflects different $\mathrm{pH}$ and Eh conditions from those of the classic metamorphic protores gondite and queluzite. For this reason the protore is here designated "bandarrite". The presence of native copper in the protore represents an uncommon association in manganese deposits.
\end{abstract}

INTRODUÇÃO O presente trabalho é resultado do estudo de um depósito de manganês contendo óxidos primários, carbonatos e silicatos. A presença de cobre nativo reveste-se de grande interesse, pois representa o primeiro exemplo descrito na literatura geológica brasileira.

Os primeiros trabalhos publicados sobre o depósito de Bandarra devem-se a Ribeiro Filho $(1969,1976)$, Machado (1977) e, mais recentemente, a Machado e Ribeiro Filho (1980)

A área objeto do presente trabalho encontra-se na extremidade sul de uma faixa de rochas metamórficas que contém dezenas de depósitos manganesíferos, distribuídos numa extensão de quase $100 \mathrm{~km}$, tendo as cidades de Brejinho das Ametistas e Jacaraci nas extremidades norte e sul, respectivamente, incluindo Urandi, Licínio de Almeida e Tauape.

O conjunto dessas rochas, que contém os depósitos de mangannês da região, é citado por Mascarenhas (in Inda, 1979) como provável estrutura do tipo greenstone belt, cuja idade deve estar contida no intervalo de 3000 a 2700 m.a.

Neste trabalho, são focalizados aspectos relativos à geologia do depósito, mineralogia, condiçzos genéticas de formação do protominério e a proposição do termo "bandarrito" para designação do mesmo.

LOCALIZAÇÃO E ACESSO O depósito de Bandarra está localizado na extremidade sul do Estado da Bahia, no município de Jacaraci, próxima à zona limítrofe com o Estado de Minas Gerais, possuindo como coordenadas geográficas os paralelos $14^{\circ} 48^{\prime} 37^{\prime \prime}$ e $14^{\circ} 50^{\prime} 36^{\prime \prime}$ de latitude sul e os meridianos $42^{\circ} 3.1^{\prime} 06^{\prime \prime}$ e $42^{\circ} 32^{\prime} 27^{\prime \prime}$ de longitude oeste, conforme indica o mapa anexo (Fig. 1).

$\mathrm{O}$ acesso à região pode ser feito pela estrada de Ferro Leste da Bahia, que liga Salvador a Belo Horizonte, passando por Brumado, Caculé e Licínio de Almeida, seguindo por Urandi, Espinosa e Montes Claros. Estradas de rodagem também ligam Jacaraci a Vitória da Conquista, na Bahia, e a Montes Claros, em Minas Gerais.

GEOLOGIA DO DEPÓSITO DE BANDARRA As rochas que ocorrem na região de Bandarra são consideradas, nios trabalhos de Inda e Barbosa (1978) e Mascarenhas (1979),

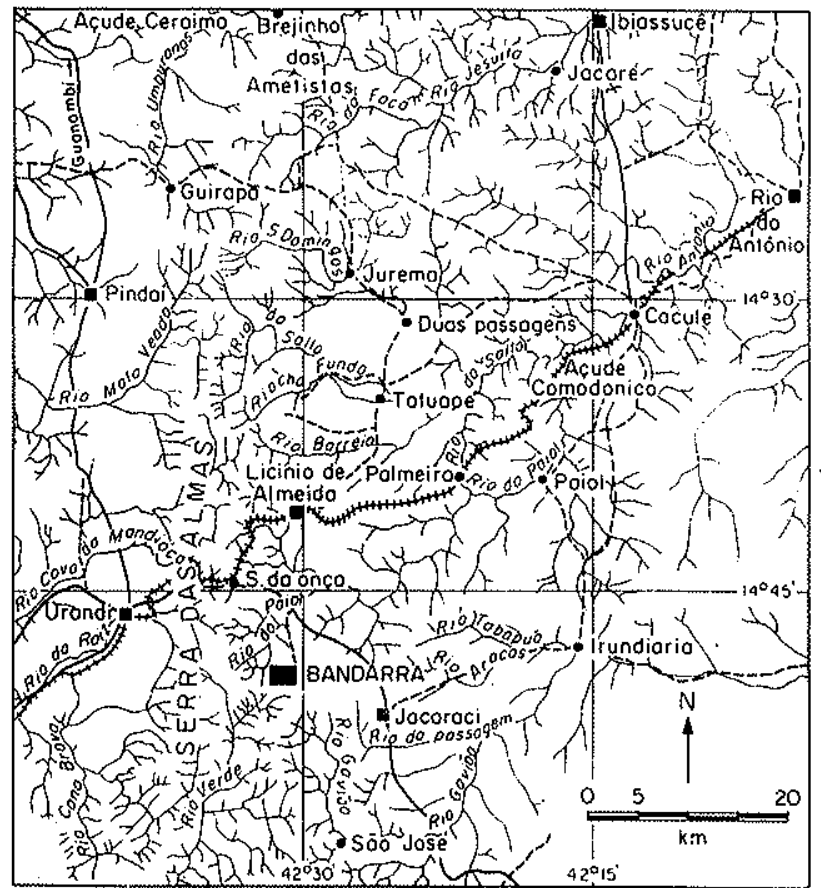

Figura l - Mapa de localizaçáo do depósito de manganês de Bandarra, Bahia

como integrantes do Complexo de Licínio de Almeida, cuja litologia está representada por uma sequiência vulcano-sedimentar do tipo greenstone belt com idade atribuída ao Proterozóico Inferior.

$\mathrm{Na}$ área do depósito de Bandarra, Machado (1977) separou três sequêencias litológicas que possuem a seguinte ordem de empilhamento: sequiência basal - micaxistos; seqüência intermediária - formação ferrífera; e sequêencia superior anfibolitos, quartzitos micáceos e micaxistos.

$\mathrm{Na}$ seqüência basal, predominam micaxistos que apresentam, em direção do topo, finas intercalações de quartzitos e quartzo-micaxistos com impregnações de manganês. $O$ exame petrográfico revela, como constituintes principais, quartzo, micas (biotita, sericita e clorita) e, como acessórios, 
zircão, titanita, rutilo, calcita e opacos. Ocorrem também microclina e plagioclásio (An 33-37), que se tornam mais freqüentes na porção inferior da sequêencia basal.

A seqüência intermediária está representada pela formação ferrífera que contém o depósito de manganês de Bandarra. Esta litologia, ao microscópio, revela estrutura com alternância de leitos de hematita e de quartzo granular.

A seqüência superior contém, da base para o topo, micaxistos, anfibólitos, quartzitos micáceos e recorrência de micaxistos. Os anfibolitos concordam com as unidades situadas acima e abaixo, alcançando espessura da ordem de pouco mais de uma centena de metros. Tais rochas, ao microscópio, revelam textura granonematoblástica, com anfibólios (hornblenda, cummingtonita-grunerita e/ou tremolita-actinolita) e epídoto, constituindo mais de $80 \%$ em volume da'rocha, aparecendo, subordinadamente, plagioclásio, biotita, turmalina e opacos.

Conquanto estejam ausentes minerais índices de metaforfísmo nas rochas de Bandarra, o aparecimento de plagioclásio de tipo intermediário e associação hornblenda-plagioclásio-epídoto refletem um conjunto de rochas formado na fácies almandina-anfibólito que, para Turner e Verhoogen (1960), atinge temperatura de $550^{\circ} \mathrm{C}$ a $750^{\circ} \mathrm{C}$ e pressão de 4000 a 8000 bars.
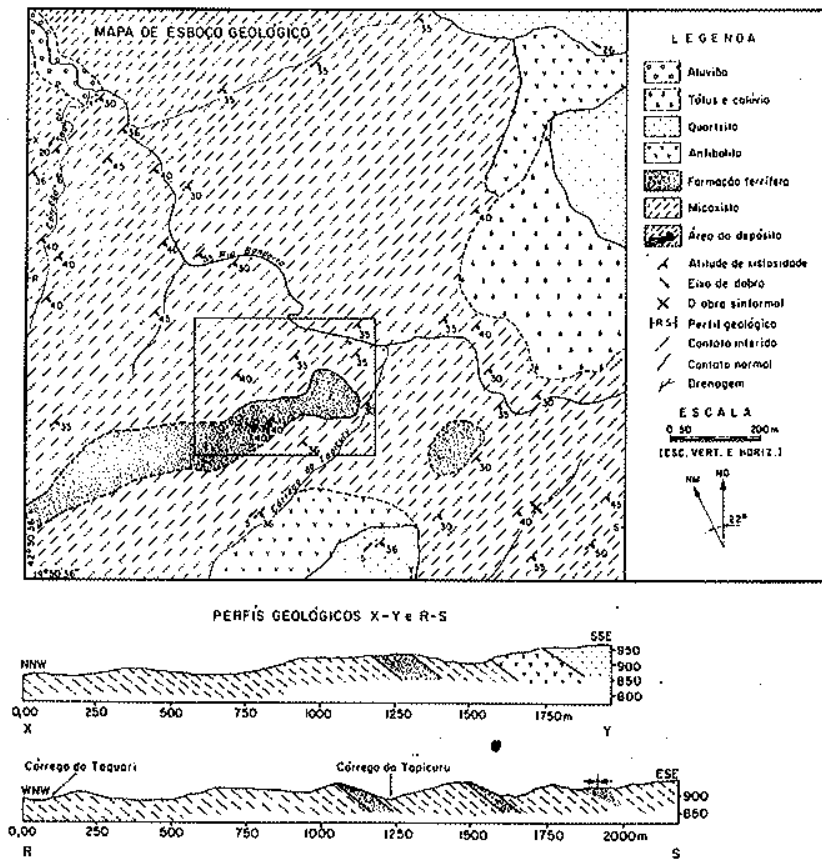

Figura 2 - Área de Bandarra, Bahia (Rômulo Machado, 1977)

\section{DEPÓSITO DE MINÉRIO Os corpos de minério de Ban-} darra ocorrem dentro da formação ferrifera sob a forma de lentes-camadas de manganês, cuja distribuição se faz em dois níveis, que apresentam gradaçðes laterais tanto na vertical como na horizontal, acompanhadas pelo decréscimo de manganês e, consequentemente, enriquecimento em ferro.

A formação ferrifera concorda $\mathrm{rom}$ os micaxistos superiores e inferiores em contatos li ógicos que se revelam sempre bruscos.

A espessura das lentes-camadas é variável, estendendo-se de poucos centímetros a um máximo de $0,85 \mathrm{~m}$, com valores médios situados ao redor de $0,20 \mathrm{~m}$. As lentes possuem extensão individual que não ultrapassa $10 \mathrm{~m}$. Por outro lado, a formação ferrífera em Bandarra possui espessura não superior a 5 ou $6 \mathrm{~m}$.

MINERALOGIA São distinguidos dois grupos de minerais: a) metamórficos, que incluem óxidos (jacobsita, hausmannita, bixbyita, hematita), silicatos (espessartita, tefroíta, alleganyita, anfibólio e mica manganesiferos) e carbonato (kutnahorita ou manganocalcita ou' manganodolomita); b) secundarios, que incluem o grupo $\alpha-\mathrm{MnO}_{2}$, malaquita, cuprita e óxido de ferro hidratado.

Os minerais de ganga inchuem aqueles formados juntamente com o protominério durante o metamorfismo, tais como: quartzo (sob a forma de metachert ou jaspe), óxido de ferro (hematita), carbonatos e silicatos manganesíferos.

DISCUSSÃO DA GÊNESE Alguns autores, como Krauskopf (1956), Krumbein e Garrels (1952), James (1951, 1954), Garrels e Christ (1965) e Borchert (1970), são unânimes em considerar as condições de pH e Eh como parâmetros mais importantes que envolvem o processo de formação e separação de ferro e manganês em condiçōes superficiais.

$\mathrm{Na}$ formação ferrífera de Bandarra, a coexistência de carbonato e minerais de manganês e ferro primários revela que as condiçoes reinantes durante a época da sedimentação eram favoráveis à formação de oxidos e carbonatos no mesmo ambiente sedimentar. Por conseguinte, seus campos de estabilidade são regidos por valores de $\mathrm{pH}$ e Eh que diferem ligeiramente. Todavia a variação desses parâmetros individualmente ou em conjunto explica, ao menos teoricamente, a coexistência, num mesmo depósito, de óxidos e carbonatos ou, ainda, carbonatos e sulfetos, embora estes últimos estejam ausentes em Bandarra.

Considerando-se que o transporte de manganês seja efetuado em solução com bicarbonato (Savage, 1939), da mesma forma que o ferro (Borchert, 1970), admite-se que no depósito de Bandarra houve uma pré-concentração num ambiente ligeiramente ácido que, por aumento progressivo do $\mathrm{pH}$, conduziu, inicialmente, à precipitação de óxido de ferro e, logo à seguir, de manganês, tornando a solução neutra ou levemente alcalina. Neste meio, a presença de metais alcalinos terrosos, particularmente $\mathrm{Ca} \mathrm{e} \mathrm{Mg}$, conduziria à precipitação de carbonato acima da limestone fence e oxide carbonate fence de Krumbein e Garrels (1952). Isso poderia ser devido à variação do potencial de oxidação da solução, o qual inibiria a precipitação de óxidos de ferro e manganês, favorecendo a dos respectivos carbonatos.

A ausência de sulfetos e grafita descarta a possibilidade de ambiente redutor para formação de seus minerais no estágio sedimentar bem como de águas estagnadas, sem circulação, que pudessem justificar um ambiente euxínico. Desse modo, admite-se a presença de uma bacia com boa circulação e oxigenação suficiente para manter um ambiente ligeiramente oxidante, com $\mathrm{pH}$ variando de neutro a levemente alcalino, estendendo-se até fracamente redutor com valores de Eh positivos.

A ocorrência de óxidos de manganês de baixa valência (bixbyita, hausmannita e jacobsita), associados a carbonato e silicatos de manganês (espessartita, tefroíta, alleganyita etc.) no protominério de Bandarra, parece não encontrar similitude com os depósitos descritos na literatura geológica.

Os termos "queluzito" e "gondito" introduzidos, respectivamente, por Derby (1901) e Fermor (1906), discutidos e redefinidos por Roy (1965) não se aplicam à qualificação do protominério encontrado em Bandarra. Rpy (op, cit.) considera os protominérios da Índia como do tipo gondito, caracterizados pela presença de óxidos de manganês de alta 
temperatura e silicatos, estando ausente o carbonato de manganês primário. Os protominérios brasileiros, contendo carbonatos e silicatos com grafita ou alabandita sem óxidos primários, são considerados como do tipo queluzito.

Ribeiro Filho (1968) descreve, para a região de UrandiLicinio de Almeida, o protominério de tipo sílico-carbonático (jazida de Barreiro dos Campos) e o do tipo óxido (Pedra Preta e Barnabé), representado, no primeiro caso, pela associação carbonato-silicato de manganês, enquanto, no segundo, por óxidos primários de alta temperatura (jacobsita, hausmannita e bixbyita).

No protominério do depósito de Bandarra coexistem óxidos de alta temperatura com silicatos e carbonatos, estando ausentes alabandita e grafita.

Os termos gondito e queluzito, no sentido clássico, não encontram correspondência no referido depósito, visto que, além de diferirem na assembléia metamórfica resultante, refletem condições sedimentares de pH e Eh diferentes das atribuídas a Bandarra. Desse modo, admite-se um protominério do tipo intermediário entre os tipos gondito e queluzito, para o qual é sugerido o termo "bandarrito".

$O$ bandarrito pode ser definido como uma rocha metamórfica de origem sedimentar (química ou bioquímica), depositada em condições ligeiramente oxidantes, contendo óxidos de ferro e manganês associados com carbonatos que, como protominério, revela a presença de óxidos de alta temperatura (jacobsita, hausmannita e bixbyita), carbonatos (kutnahorita, manganocalcita ou manganodolomita) e silicatos manganesiferos (tefróta, alleganyita, anfibólio $\mathrm{e}$ mica).

A ocorrência de cobre nativo representa uma associação pouco comum em depósitos dessa natureza, razão pela qual a atribuição de uma origem epigenética ou singenética deve levar em conta as seguintes observaçōes: $a$ ) distribuição restrita do cobre nativo nas lentes de minério, ocorrendo em associação com malaquita e cuprita; $b$ ) ausência, no local de ocorrência, de veios de quartzo hidrotermal bem como de corpos intrusivos que apresentem ligação direta com o cobre; c) os corpos de anfibolitos revelam conteúdo em cobre na faixa de 65 a 112 ppm enquanto, que, no minério, está entre 30 e 110 ppm; e $d$ ) ao microscópio, o cobre distribui-se com frequêencia na ganga carbonática associado geralmente com hausmannita.

A ação do intemperismo sobre os minerais primários propiciou a formação de óxidos de manganês secundários, tanto na forma de lentes-camadas dentro da formação ferrífera, por lixiviação de sílica, ferro e carbonato, como na forma de minério do tipo granzon, evoluído a partir da dissolução e reprecipitação de horizontes manganesíferos.
CONCLUSõEs O depósito de manganês de Bandarra faz parte de um conjunto de rochas de natureza vulcano-sedimentar que compõe-o Complexo de Licínio de Almeida, cujas sequuências litológicas e estruturas geológicas são correlacionadas por Mascarenhas (1979) com as do tipo greenstone belts, com idade atribuída ao Proteorozóico Inferior.

A interação dos dados de temperatura, obtidos a partir da associação mineralógica das rochas encaixantes com as do corpo mineralizado, sugere que os valores de temperatura alcançados durante o metamorfismo foram ao redor de $600^{\circ} \mathrm{C}$ a $650^{\circ} \mathrm{C}$.

Com base na mineralogia e na textura do minério, admite-se que a transformação de óxidos com alta valência em óxidos de baixa valência ocorreu durante o metamorfismo regional que afetou a área.

A associação mineralógica encontrada no protominério de Bandarra revela características que diferem das descritas nos protominérios indianos e brasileiros, respectivamente, gondito e queluzito. Por esta razão, o referido protominério deve ser considerado como do tipo intcrmediário, provavelmente mais próximo do tipo gondito que do queluzito, para o qual é sugerido o termo "bandarrito".

A coexistência de carbonato, no sedimento original, com óxido de manganês de alta valência pode ser explicada com base nos diagramas de Krumbein e Garrels (1952), e Bricker (1965) para condições de formação em superfície $\left(25^{\circ} \mathrm{C}\right.$ e 1 atm de pressão).

A formação de depósito do tipo granzon foi condicionada pela conjugação de fatores fisiográficos com vegetação exuberante e condições excelentes de circulação de água.

O sedimento original que proporcionou o depósito de Bandarra constituiu-se de óxidos e/ou hidróxidos de ferro e manganês contendo chert (ou jaspe) e carbonato(s) contendo impurezas argilosas.

A associação de cobre nativo no depósito de manganês de Bandarra se faz, de preferência, no domínio carbonático, sugerindo uma deposição contemporânea à do carbonato de manganês.

Embora Bandarra seja um depósito de grandẹ interesse para estudos mineralógicos, genéticos etc., do ponto de vista econômico representa concentração de pouco valor, visto que tanto para manganês quanto para cobre as reservas são muito pequenas.

Agradecimentos $\mathrm{O}$ autor consigna seus agradecimentos à Companhia de Mineração Urandi S/A., pelo apoio de material técnico e financeiro, e ao Professor. Doutor Evaristo Ribeiro Filho, pela orientação dispensada durante a execução do trabalho de Mestrado.

\section{BIBLIOGRAFIA}

BORCHERT, H. $-1970-$ On the Ore-Deposition and Geochemistry of Manganese. Min. Deposita 5(3):300-314.

BRICKER, O.P. - 1965 - Some Stability Relations in the System Mn$\mathrm{O}-\mathrm{H}_{2} \mathrm{O}$ at $25^{\circ} \mathrm{C}$ and one Atmosphere Total Pressure. Amer. Mineral 50(9): 1296-1354.

DERBY, I.A. - 1901 - On the Manganese Ore Deposits of the Queluz (Lafayette) District, Minas Gerais, Brazil. Amer. Jour. Sci. Xl1:18-32.

GARRELS, M.R. e CHRIST, C.L. - 1965 - Solutions, Minerals, and Equilibria. Harper \& Row, New York, $450 \mathrm{pp}$.

INDA, H.A.V. e BARBOSA, J. F. - 1978 - Texto Explicativo para o Mapa Geológico do Estado da Bahia, escala 1:1000 000. SME/CPM, Salvador, $137 \mathrm{pp}$.

JAMES, H.L. - 1951 - Iron Formation and Associated Rocks in the Iron River District, Michigan. Geol. Soc. America Bull 62(3):251-266.
JAMES, H.L. - 1954 - Sedimentary Facies of Iron-Formation. Econ. Geol. 49(3):235-293.

KRAUSKOPF, B.K. - 1956 - Separation of Manganese from Iron in Sedimentary Processes. Geoch. Cosmoch. Acta 12(1/2):85-93.

KRUMBEIN, W.C. e GARRELS, R.M. - 1952 - Origin and Classification of Sediments in Terms of $\mathrm{pH}$ and Oxidation-Reduction Potencials. $J$. Geol. 60(1):1-33.

MACHADO, R, - 1977 - Geologia e Gênese do Depósito de Manganês de Bandarra, Município de Jacaraci, Bahia. Dissertação de Mestrado apresentada ao Instituto de Geociências da Universidade de São Paulo, 109 pp.

MACHADO, R. e RIBEIRO FILHO, E. - 1980 - Geology and Genesis of Deposit of Bandarra, Urandi District, Brasil XXVI Intern. Geol. Congr., Paris 1980,3 , Sec. 13, p. 962 
MASCARENHAS, J.F. - 1979 - Estruturas do Tipo "Greenstone Belt" no Leste da Bahia. In: H. Inda (ed, texto) Geologia e Recursos Minerais do Estado da Bahia, vol. Il SME/CPM, Salvador, $165 \mathrm{pp}$.

RJBEIRO FILHO, E. - 1968 - Geologia da Regiåo de Urandi e das Jazidas de Manganês Pedra Preta, Barreiro dos Campos e Barnabé, Bahia. Tese de Livre-Docência apresentada à Faculdade de Filosofia Ciências e Letras da Universidade de São Paulo, 82 pp.

RIBEIRO FILHO, E. - 1969 - Cobre nativo associado a oxidos de manganês em Urandi, Bahia, Anais XXIII Congr. Bras. Geol., pp 191-194, Salvador.

RIBElRO FILHO, E. - 1976 - Textures indicating the Genesis of Manganeses Ores in the Area of Urandi. Abstracts (3) XXV Intern. Geol. Congr. Sidney, Austrália.
ROY, S.P. - 1965 - Comparative Study of the Metamorphosed Manganese Protores of the World. The Problem of the Nomenclature of the Gondites and Kodurites. Econ. Geol. 60(6):1238-1260.

SAVAGE, W.S. - 1939 - Solution, Transportation and Precipitation of Manganese. Econ. Geol. 31(3):278-297.

TURNER, F.J. e VERHOOGEN, J. - 1960 - Igneous and Metamorphic Petrology, 2nd. ed., McGraw-Hill Book Co. Inc., New York.

MANUSCRITO

Recebido em 12 de jutho de 1982 Revisão aceita em 17 de janeiro de 1983 